\title{
Enquistación in vitro de Giardia lamblia: análisis por electroforesis bidimensional de proteínas expresadas diferencialmente
}

\author{
Paula C. Hernández ${ }^{1}$, María Leonor Caldas ${ }^{3}$, Moisés Wasserman ${ }^{1,2}$ \\ ${ }^{1}$ Laboratorio de Investigaciones Básicas en Bioquímica, LIBBIQ, Departamento de Química, Facultad de \\ Ciencias, Universidad Nacional de Colombia, Bogotá D.C., Colombia. \\ 2 Laboratorio de Bioquímica, Instituto Nacional de Salud, Bogotá, D.C., Colombia. \\ ${ }^{3}$ Unidad de Microscopía y Análisis de Imágenes, Instituto Nacional de Salud, Bogotá, D.C., Colombia.
}

La reconstrucción in vitro del ciclo de vida de Giardia lamblia es un excelente instrumento para el estudio de la biología molecular del parásito. El presente trabajo pretende contribuir al desarrollo de algunas técnicas por las cuales se puede definir mejor un modelo de diferenciación celular del parásito. El estudio presenta un protocolo de enquistación in vitro y establece un método para el aislamiento y la purificación de los quistes producidos, cuyas características morfológicas, por microscopía de luz, coinciden con las de los quistes obtenidos in vivo. Se estudió el mapa de las proteínas de G. lamblia por medio de electroforesis bidimensional de alta resolución y de electroforesis en una dimensión. Estos estudios mostraron que la mayoría de las proteínas del parásito son de carácter ácido. Se amplió, con base en ese resultado, la resolución de la región ácida por medio de un isoelectroenfoque de $\mathrm{pH}$ 4-7 en la primera dimensión. Se encontraron diferencias en la expresión de las proteínas durante el proceso de enquistación. Se obtuvieron, además, imágenes por microscopía de luz y electrónica de transmisión que permitieron observar morfológica y ultraestructuralmente las células producidas durante el proceso de la enquistación.

Palabras clave: Giardia lamblia, enquistación, microscopía electrónica, electroforesis bidimensional, diferenciación, parásito, protista.

Giardia lamblia in vitro encystation: two dimensional electrophoresis analysis of differences in protein expression

The reconstruction of Giardia lamblia life cycle in vitro is an excellent tool for the study of the parasite's molecular biology. The present work describes techniques developed that better define parasite differentiation. An encystation protocol is presented along with a method for isolation and purification of the produced cysts. The cyst morphology at the light microscopy level is identical to that of in vivo cysts. A two-dimension protein map obtained by high-resolution electrophoresis indicated that most of the parasite's proteins are acid. Based on this result, the two dimension gel electrophoresis used a $\mathrm{pH}$ 4-7 gradient in the first, isoelectric focusing dimension. Differences in protein expression during the stages of encystation were clearly discerned, as well as images of the parasite obtained by light and by transmission electron microscopy that describe the morphological and the ultrastructural changes that occur as the cysts are produced in vitro.

Key words: Giardia lamblia, encystation, electronic microscopy, two-dimensional electrophoresis, differentiation, parasite, protista.

\begin{abstract}
Correspondencia:
Laboratorio de Bioquímica, Instituto Nacional de Salud; telefax 220 0922; phernatehortua@yahoo.com
\end{abstract}

Recibido: 03/05/02; aceptado: 26/08/02
Giardia lamblia es un parásito protozoario ampliamente diseminado en el mundo, pero especialmente en las poblaciones más desprotegidas que no cuentan con servicios sanitarios adecuados. Produce una patología 
intestinal llamada giardiosis que puede conducir a problemas de mala absorción y retraso en el crecimiento. El ciclo de vida de Giardia presenta dos formas morfológicamente distintas, trofozoítos y quistes. La enfermedad es causada por el trofozoíto y se presenta frecuentemente con diarrea aguda o crónica. Los trofozoítos colonizan la parte superior del intestino delgado del hospedero, donde, por mecanismos desconocidos, pueden diferenciarse en quistes que luego pueden pasar a las heces (1).

G. lamblia se considera un excelente sistema para estudiar la evolución de los procesos celulares fundamentales porque es posiblemente el eucariote vivo más antiguo, un verdadero fósil biológico (2). Por tanto, es de suponer que los mecanismos de señalización para la diferenciación son los más fundamentales y simples y se podría contar con un modelo más definido y sencillo para el estudio de problemas que, en otros eucariotes más evolucionados, se tornan excesivamente complejos.

Además, en el laboratorio se puede reproducir completamente el ciclo de vida del parásito con técnicas sencillas de cultivo axénico y, para el caso que nos interesa en este trabajo, se puede estudiar la enquistación con el fin de lograr una simulación de las condiciones medioambientales del parásito in vivo.

La enquistación de $G$. lamblia in vitro se ha demostrado mediante criterios morfológicos, inmunológicos y bioquímicos (3). Durante la formación del quiste, los trofozoítos sufren cambios morfológicos y bioquímicos importantes: 1) recepción de los estímulos para la enquistación y la consecuente activación de genes específicos; 2) biogénesis de organelos secretorios y síntesis, empaque, transporte y liberación de materiales para la pared del quiste, y 3) ensamblaje de la pared (4).

Sorprendentemente, a pesar de las expectativas señaladas, $G$. lamblia se ha estudiado relativamente poco y las referencias bibliográficas con las que se cuenta presentan una imagen a veces contradictoria e incipiente sobre aspectos moleculares y bioquímicos de su diferenciación. En este estudio se pretendió llevar a cabo una estandarización de las condiciones necesarias para que se realice de una forma eficiente el proceso de enquistación; detectar las proteínas involucradas en la diferenciación de trofozoíto a quiste, entre las que se encuentran las CWP1 y CWP2 (cyst wall proteins) (4), por medio de electroforesis bidimensional (una técnica de análisis de alta resolución) y obtener imágenes por microscopía electrónica de transmisión de las dos formas de diferenciación de una cepa colombiana.

\section{Materiales y métodos \\ Cultivo de parásitos}

Los trofozoítos de G. lamblia (cepa MHOM/Co/ 97/G1, proporcionada por el Laboratorio de Parasitología del Instituto Nacional de Salud) se cultivaron axénicamente a $34^{\circ} \mathrm{C}$ en el medio de Diamond TYI-S-33 (5), suplementado con $0,5 \mathrm{mg} /$ $\mathrm{ml}$ de bilis, $10 \%$ de suero bovino, $100 \mathrm{U} / \mathrm{ml}$ de penicilina y $0,1 \mathrm{mg} / \mathrm{ml}$ de estreptomicina y ajustado a un $\mathrm{pH}$ de 7,0 (6) en tubos de borosilicato de $16 \mathrm{ml}$.

\section{Enquistación in vitro}

El medio básico de enquistación consiste en el TYI-S-33 de cultivo normal ajustado a un $\mathrm{pH}$ de 7,8. Se probaron diferentes concentraciones de bilis bovina ( 5 a $15 \mathrm{mg} / \mathrm{ml}$ ). Estos ensayos se llevaron a cabo en tubos de poliestireno de $5 \mathrm{ml}$. En algunos se evaluó el efecto de la variación de la cantidad de trofozoítos iniciales que son sometidos al estímulo (2 a $10 \times 10^{6}$ trofozoítos/ $\mathrm{ml}$ ). En los siguientes ensayos, la inducción se llevó a cabo con $10^{7}$ trofozoítos a $34^{\circ} \mathrm{C}$ en el medio anteriormente descrito, con una duración del estímulo de 24 horas (o según lo que se indica en el texto), al cabo de las cuales se retornaron al medio de crecimiento normal donde fueron incubados durante 24 horas más. Después de la incubación en el medio de enquistación a $34^{\circ} \mathrm{C}$, los parásitos se recolectaron enfriando los tubos en hielo durante 10 minutos y centrifugando a $883 \mathrm{~g}$ durante 5 minutos. Para lisar los trofozoítos y algunos quistes no totalmente diferenciados, los sedimentos de células se resuspendieron primero en una solución hipotónica de $\mathrm{NaCl}$ 0,8 $\mathrm{M}$ y posteriormente se lavaron varias veces con agua a $4{ }^{\circ} \mathrm{C}$ (hasta lisis completa de los 
trofozoítos). El sedimento de trofozoítos 'fantasma' y quistes se mezcló con $10 \mathrm{ml}$ de Percoll ${ }^{\mathrm{TM}}$ (Pharmacia) a una concentración de $\mathrm{NaCl} 0,15 \mathrm{M}$, con una densidad de $1,07 \mathrm{~g} / \mathrm{ml}$, y se centrifugó a $18.000 \mathrm{~g}$ durante 30 minutos a 4 ${ }^{\circ} \mathrm{C}$ en un rotor de ángulo fijo de $35^{\circ}$ (centrífuga Jouan GR 20 22). La fracción que contenía los quistes libres de trofozoítos $( \pm 1,048 \mathrm{~g} / \mathrm{ml})$ se recolectó y resuspendió en $1 \mathrm{ml}$ de agua doblemente destilada para conteo en hemocitómetro.

\section{Electroforesis de proteínas}

Se corrieron geles unidimensionales de SDSpoliacrilamida (7) de lisados crudos de trofozoítos y células enquistantes. Los geles bidimensionales se corrieron según Celis et al. (8), utilizando para el isoelectroenfoque (IEF) tiras con gradiente lineal preelaborado de $\mathrm{pH}$ de 3-10 y 4-7 (Amersham Pharmacia) y para la segunda dimensión, geles de SDS-poliacrilamida al 10\%. En cada caso, la visualización de las proteínas en los geles tanto de una como de dos dimensiones se realizó con solución de Coomassie G-250 (USB), con plata amoniacal (9) y con el colorante fluorescente Sypro Orange Stain ${ }^{\mathrm{TM}}$ (Molecular Probes).

\section{Microscopía de luz}

Las células, tanto trofozoítos como quistes, se fotografiaron en montajes húmedos en láminas preparadas directamente del sedimento obtenido por centrifugación en cada caso, por medio de un microscopio óptico Zeiss Axiophot, con objetivos Zeiss 10X, 40X y 100X (Unidad de Microscopía y Análisis de Imágenes, INS).

\section{Microscopía electrónica de transmisión}

Alícuotas de 0,1 $\mathrm{ml}$ de cada tipo de célula (trofozoítos y quistes) que contenían aproximadamente $5 \times 10^{6}$ parásitos se lavaron siete veces con una solución amortiguadora de fosfatos, $0,1 \mathrm{M}, \mathrm{pH} 7,27$, para eliminar el medio de cultivo y se recolectaron por centrifugación a $2.000 \mathrm{rpm}(230 \mathrm{~g})$. El sedimento en seco se mezcló con una solución de agarosa al 1\% en buffer fosfato para obtener un material solidificado que pudiera trabajarse con más facilidad que las células en suspensión. Se realizó una fijación inmediata del bloque de agarosa con glutaraldehído al $3 \%$ en buffer fosfato durante 3 horas a $4{ }^{\circ} \mathrm{C}$ y, después, se hicieron 4 lavados con buffer fosfato durante tres minutos cada uno. Se realizó una postfijación con $\mathrm{OsO}_{4}$ al $1 \%$ en buffer fosfato durante dos horas a temperatura ambiente. Se realizaron 5 lavados con el mismo buffer durante 3 minutos, anteriores a la subsiguiente deshidratación con un gradiente ascendente de soluciones de etanol en concentraciones de $50,70,80,95 \%$ durante 10 minutos en cada una y, luego, con etanol absoluto durante 20 minutos dos veces.

Adicionalmente, se colocaron las muestras en óxido de propileno durante 20 minutos como paso previo a la infiltración con resinas epóxicas. La infiltración se llevó a cabo con óxido de propileno y resina epon-araldita para luego ser colocadas en resina pura, con 2 cambios cada 4 horas a temperatura ambiente. La polimerización de estas muestras se realizó a una temperatura de $68^{\circ} \mathrm{C}$ durante 48 horas. Posteriormente, se obtuvieron cortes semifinos de $500 \mathrm{~nm}$ y finos de 60 a 90 $\mathrm{nm}$ en un ultramicrótomo LKB (Ultratome III $8802 \mathrm{~A}$ ), los cuales se montaron sobre rejillas de cobre que se colocaron con acetato de uranilo al $6 \%$ en alcohol y citrato de plomo. Los cortes finos se observaron en un microscopio electrónico Zeiss EM-109 en la Unidad de Microscopía y Análisis de Imágenes del Instituto Nacional de Salud.

\section{Resultados}

\section{Enquistación in vitro}

Se realizaron ensayos preliminares en los que se hizo un sondeo de cómo reaccionaría la cepa frente al estímulo de enquistación, partiendo de un inóculo de 4,8 $\times 10^{6}$ trofozoítos totales en tubos de $5 \mathrm{ml}$ con un medio de cultivo ajustado a un $\mathrm{pH}$ de 7,8 y concentraciones de bilis que variaron entre 5 y $15 \mathrm{mg} / \mathrm{ml}$. Se observó el comportamiento que tienen los parásitos al ser sometidos al medio de diferenciación por un período de 48 horas en las diferentes concentraciones de bilis y el resultado fue una evidente disminución en la cantidad de células totales encontradas al final del estímulo. El porcentaje de células totales al final del experimento con respecto al inóculo inicial muestra valores que son tan bajos como el $6 \%$ de la población inicial cuando se incuban en medio con $15 \mathrm{mg} / \mathrm{ml}$ de bilis (datos no 
mostrados). Por otro lado, la figura 1B muestra que, para las concentraciones de bilis usadas en este ensayo, el porcentaje de enquistación oscila entre 3 y $5 \%$ con un rendimiento mayor para la concentración de $7,5 \mathrm{mg} / \mathrm{ml}$ de bilis (5,44\%). Sin embargo, hay que tener en cuenta que las características morfológicas de los quistes obtenidos a esta concentración y superiores, sugieren una baja viabilidad comparada con la de los obtenidos a una concentración de $5 \mathrm{mg} /$ $\mathrm{ml}$ de bilis (aspecto que será expuesto más adelante).

Como resultó evidente del ensayo anterior que las concentraciones altas de bilis $(\geq 7,5 \mathrm{mg} / \mathrm{ml})$ son tóxicas para los parásitos, el tiempo de duración del estímulo también resulta ser un factor clave para la obtención de una tasa alta de enquistación. Se logró establecer que al
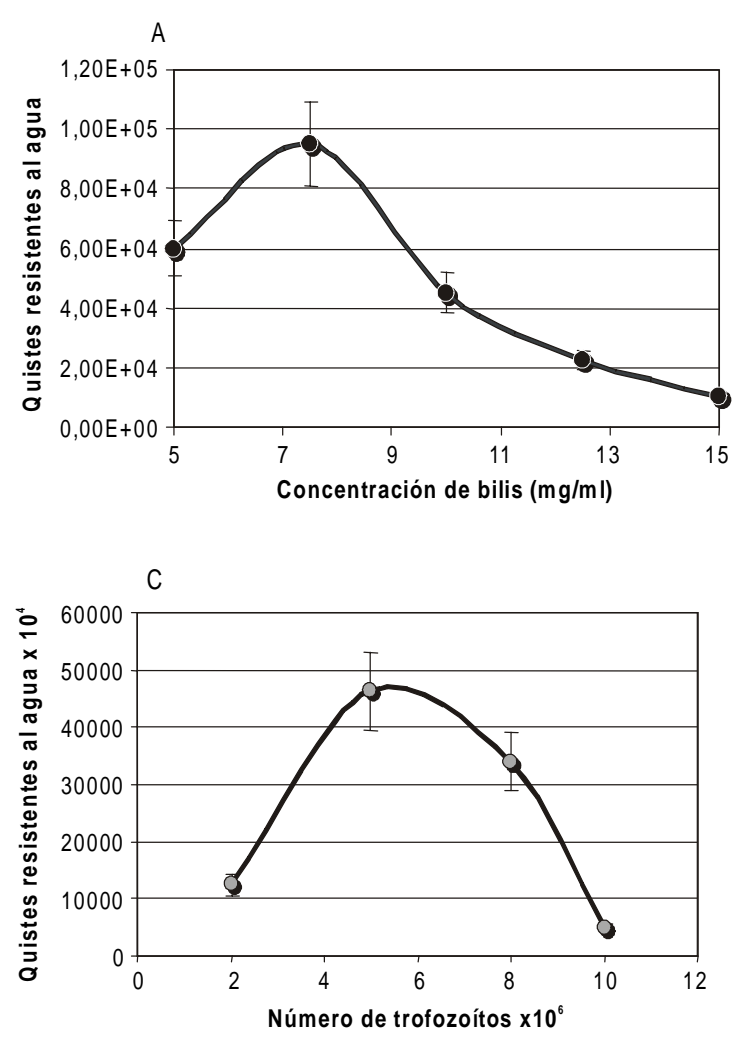

someter los parásitos a 24 horas en el medio de enquistación y otras 24 con medio de cultivo se pudo lograr una diferenciación del 14\% (datos no mostrados).

Un factor importante que podría estar influyendo en la eficiencia de enquistación es la cantidad de parásitos de la que se parte para realizar los diferentes ensayos debido a que cuando se llega a una cierta cantidad de trofozoítos en el tubo de cultivo el crecimiento se detiene, como lo mostraron Bastidas y Santamaría (10) en estudios anteriores con esta cepa, en los cuales la densidad máxima en este punto es 2,2 a 2,8 x $10^{6}$ trofozoítos $/ \mathrm{ml}$. Se hicieron ensayos variando el número de trofozoítos de partida, con una concentración de bilis de $5 \mathrm{mg} / \mathrm{ml}$ y un tiempo de estímulo de 48 horas (figura 1C y 1D). Los resultados muestran que es evidente el efecto
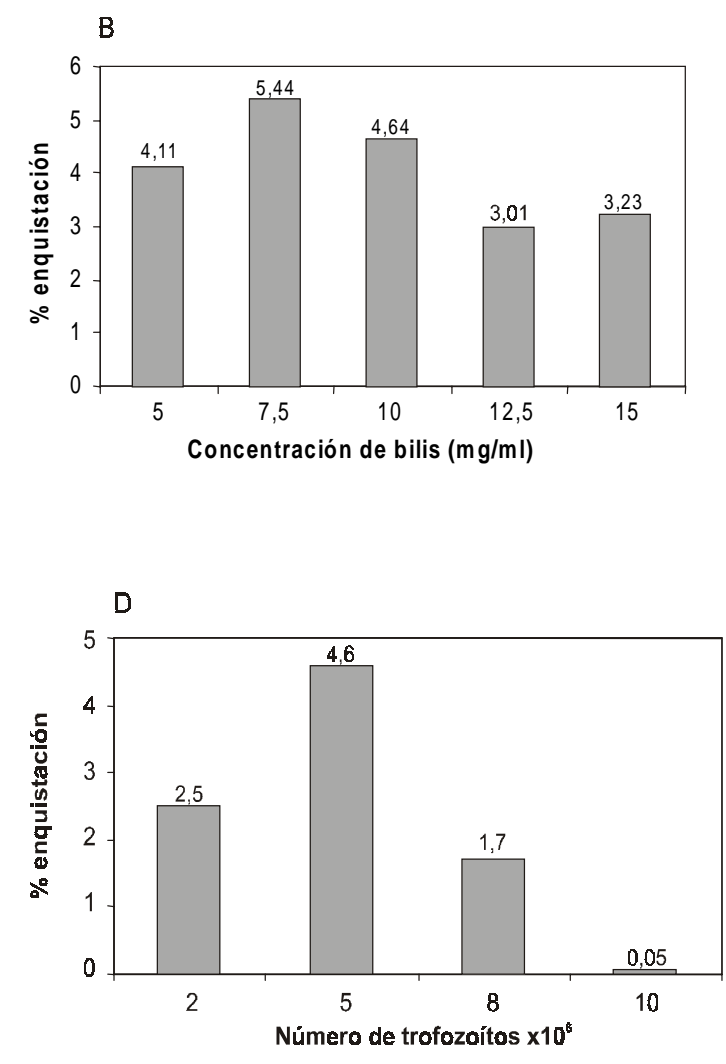

Figura 1. Efecto de la concentración de bilis en la enquistación. A. Cantidad de quistes resistentes al agua a las concentraciones de bilis indicadas. B. Porcentaje de enquistación, calculado según la población total de trofozoítos y quistes obtenida después del estímulo. Efecto del inóculo de trofozoítos de partida en la enquistación. C. Cantidad de quistes resistentes al agua obtenidos con el inóculo indicado. D. Porcentaje de enquistación con respecto a la población total al final del estímulo. Ensayos realizados en tubos de $5 \mathrm{ml}$. 

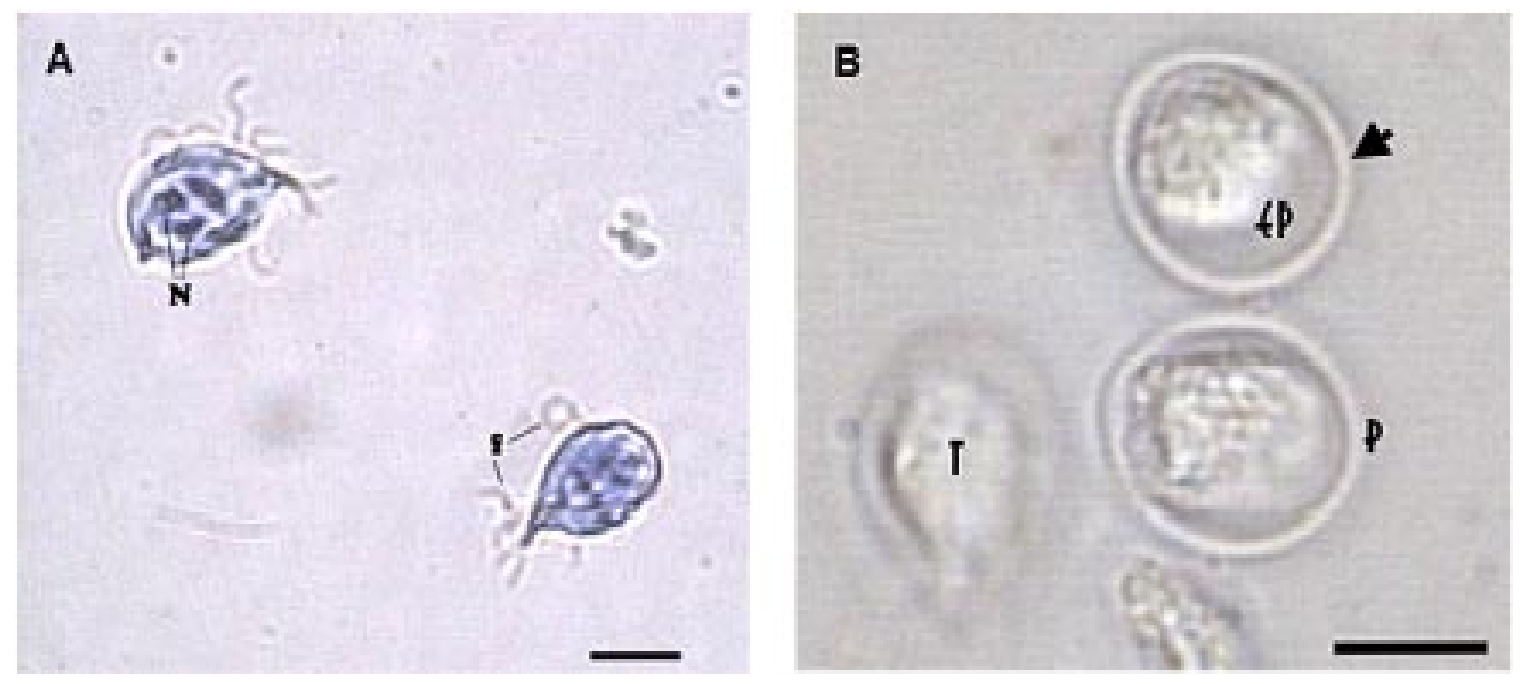

Figura 2. Micrografías por microscopía de luz de trofozoítos y quistes derivados in vitro de Giardia lamblia. A. Trofozoítos. f: flagelos; N: núcleos, teñidos con Giemsa. B. Quistes. La flecha indica el quiste no viable. P: pared de quiste; T: trofozoíto; ep: espacio peritrófico. Lugol. Barras $=5 \mathrm{~mm}$.

que tiene la concentración de células que son sometidas al estímulo de la enquistación. Se observa en la figura $1 \mathrm{C}$ que una cantidad de 5 a $6 \times 10^{6}$ trofozoítos totales en tubos de $5 \mathrm{ml}(1 \mathrm{a}$ $1,2 \times 10^{6}$ trofozoítos $/ \mathrm{ml}$ ) presenta los mejores porcentajes de enquistación $(4,6 \%)$ y que en 10 $\times 10^{6}$ células totales $\left(2 \times 10^{6}\right.$ trofozoítos $\left./ \mathrm{ml}\right)$ la diferenciación es mínima $(0,05 \%)$.

\section{Observaciones morfológicas de los dos estadios de vida}

Trofozoítos: en la figura 2A se aprecian claramente por microscopía de luz las características más generales de los trofozoítos, como su forma de pera, dos núcleos, flagelos y los cuerpos medianos localizados debajo de los núcleos. El tamaño es aproximadamente de 10$12 \mu \mathrm{m}$ de longitud por 7-8 $\mu \mathrm{m}$ de ancho.

Quistes: la pared distintivamente gruesa (aproximadamenrte, 0,4 $\mu \mathrm{m}$ ) es notoria en los quistes, así como su forma oval o en algunos casos redonda, refractilidad y perfiles de organelos citoplásmicos, como se aprecia en la figura 2B. Los quistes formados in vitro presentan dos tipos morfológicos diferentes, basados en la apariencia de su citoplasma (11). Un fenotipo está caracterizado por una pared bien definida y un pequeño espacio entre el citoplasma y la pared que se denomina espacio peritrófico. Otro fenotipo muestra un citoplasma recogido y distorsionado con un gran espacio peritrófico (ep) que lo separa de la pared, aunque ésta esté siempre intacta, como el quiste marcado con la flecha en la figura 2B.

Un comportamiento especial que tienen los quistes obtenidos mediante diferenciación en el laboratorio es su tendencia a agruparse en 'racimos', lo que posiblemente se deba a unión por proteínas de la pared o asociadas con ella, lo cual, aparentemente, no se presenta en quistes aislados de pacientes con giardiosis sintomática.

Microscopía electrónica de transmisión: la ultraestructura de los trofozoítos de G. lamblia se puede reconocer en las micrografías electrónicas de la figura 3. En los trofozoítos se destacan los dos núcleos con su membrana nuclear muy bien definida, axonemas flagelares (Ax) con un arreglo de microtúbulos de $9+2$, típico en la mayoría de los eucariotes; el disco ventral, más detallado en el panel superior derecho $B$, en el que se aprecian el conjunto de las microcintas y microtúbulos de los que está compuesto, así como su forma de copa. Se realizaron mediciones de longitud de los parásitos sobre las fotografías de microscopía electrónica y se obtuvo un valor promedio de $8,1 \mathrm{~mm}$ de 


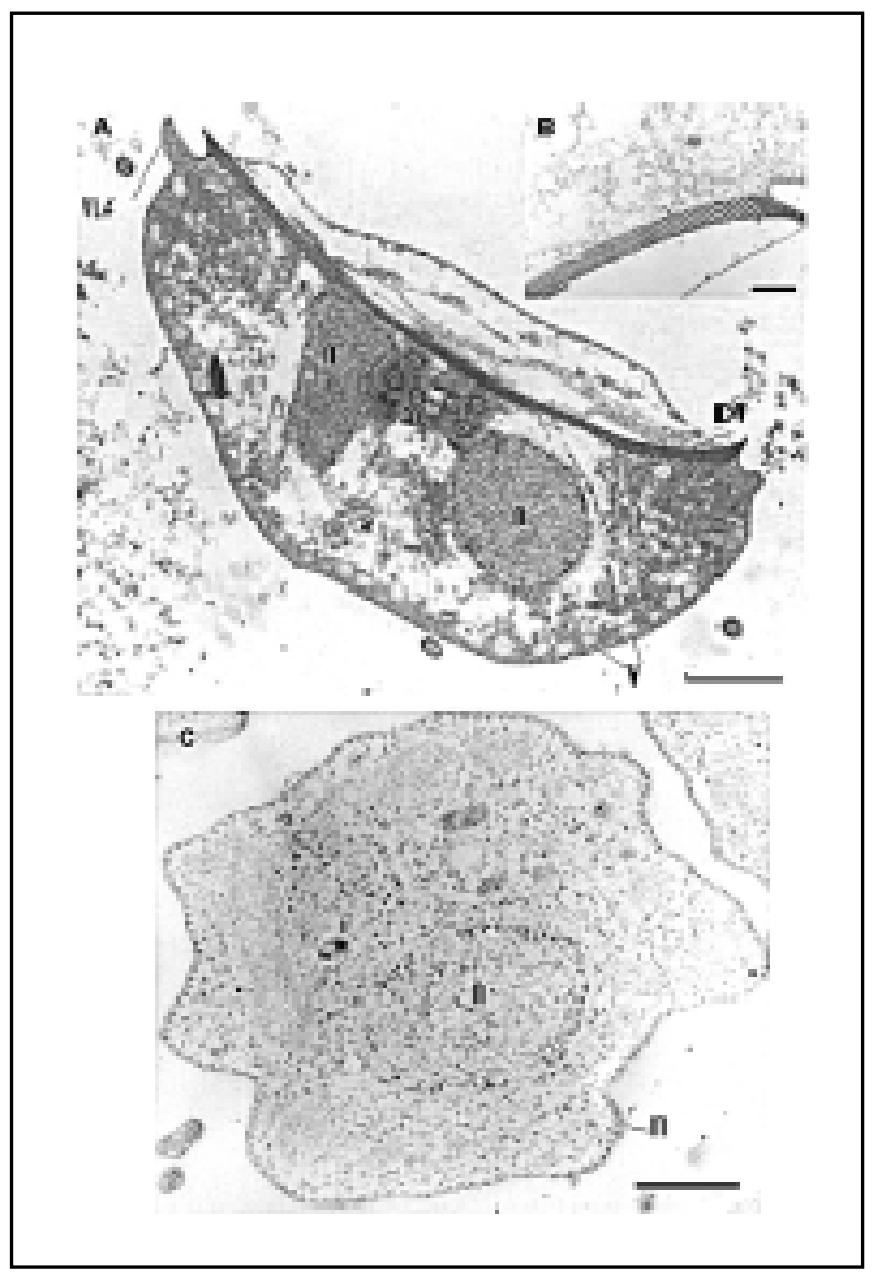

Figura 3. Ultraestructura de trofozoíto y quiste de Giardia lamblia obtenidos in vitro. A. Perfil de sección transversal de trofozoítos. N: núcleos; Ax: axonemas; VLF: flanco ventro-lateral; DV: disco ventral; V: vacuolas. Barra $=1 \mathrm{~mm}$. B. Detalle de disco ventral. Barra=0,3 mm. C. Quiste. N: núcleo; m: membrana + microtúbulos. Barra $=1 \mathrm{~mm}$.

ancho y un diámetro de $1,5 \mathrm{~mm}$ por cada uno de sus núcleos. Estos valores son muy cercanos a los informados para trofozoítos de cepas aisladas en otros países; sin embargo, hay que señalar el hecho de que este criterio de discriminación es muy poco específico. Los cortes transversales de las muestras de quistes obtenidos in vitro (panel C) muestran unas estructuras no reportadas antes en la literatura, las cuales son una serie de cuerpos de forma asimétrica con una delgada membrana bordeada de dupletas de microtúbulos que se distribuyen uniformemente a lo largo de toda la periferia. En el interior se encuentra un aparente núcleo y otros organelos que no son fácilmente distinguibles. Es importante anotar que estos cuerpos no corresponden en su morfología a trofozoítos, como se describió en el panel $A$; adicionalmente, no se definen estructuras clásicas como el disco ventral ni los axonemas característicos.

Electroforesis de proteínas: el gel unidimensional de la figura 4 muestra diferencias notorias entre los dos carriles, especialmente en los pesos moleculares cercanos a $30 \mathrm{kDa}$ (encerrados en la elipse), en donde los trofozoítos presentan bandas intensas de 28 y $32 \mathrm{kDa}$, y de 85, 65, 48 y $35 \mathrm{kDa}$, aproximadamente, que no se ven en los quistes. Por otra parte, se ve una banda muy notoria en los quistes alrededor de los $73 \mathrm{kDa}$, que no se observa en el carril de los trofozoítos.

Es evidente que hay una expresión de proteínas diferentes en el proceso de enquistación que se quiso observar con más detalle usando 


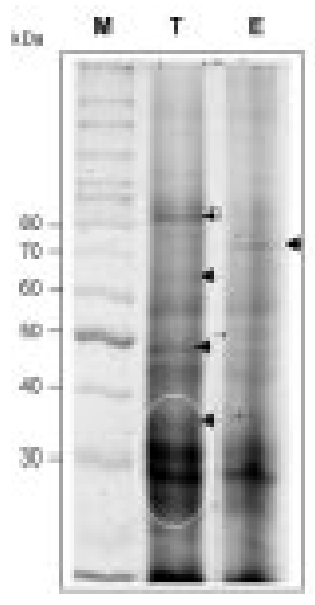

Figura 4. SDS-PAGE de proteínas de Giardia lamblia en gel $10 \%$. T: trofozoítos; E: quistes y enquistantes; M: marcador de peso molecular (Gibco), teñido con Sypro ${ }^{\mathrm{TM}}$ Orange Stain.

electroforesis de dos dimensiones. Se obtuvo el mapa electroforético bidimensional de trofozoítos en un rango lineal de punto isoeléctrico de 3-10 (para la primera dimensión) con el fin de observar la distribución de la expresión de las proteínas (figura 5A). Se observó que la gran mayoría de las proteínas o, por lo menos, las más abundantes en G. lamblia, son de carácter ácido y se localizan en el rango de $\mathrm{pH}$ de 3 a 6 . Una tinción adicional con plata descubrió algunas pocas proteínas en la región de $\mathrm{pH} 7$. Una proteína o grupo de proteínas con un peso molecular aproximado de $33 \mathrm{kDa}$, marcadas en la figura con la flecha a, son especialmente abundantes y, posiblemente, pueden corresponder al grupo de proteínas llamadas giardinas, exclusivas de este parásito, y que componen las microcintas del disco ventral. Se han hallado 23 distintas con puntos isoeléctricos en un rango de $\mathrm{pH}$ de 5,0 a 6,5 $(12,13)$.

Unas proteínas particulares son las tubulinas que se encuentran alrededor de los 50-60 kDa con un punto isoeléctrico de 5 y que podrían corresponder a las marcadas con la flecha $b$, que en el parásito se hallan en los microtúbulos que también componen el disco ventral, además de los cuerpos medianos y flagelos. Otras proteínas que se pueden identificar como posibles en este gel, y que se señalan en la figura, son la actina (c) y centrina (d) del citoesqueleto.

En el panel B de la figura 5 se muestran las proteínas de trofozoítos en un gel cuya primera dimensión se corrió entre $\mathrm{pH} 4$ y 7 ; se tienen (a) giardinas y (b) tubulinas como referencia general para comparar el patrón de expresión. Los parásitos que son sometidos a un estímulo de enquistación de 48 horas (panel $\mathrm{C}$, figura 5) no muestran, en las regiones de $\mathrm{pH}$ de 5 a 6 y en el rango de peso molecular de 50-70 kDa, las mismas proteínas que los trofozoítos. Esto se evidencia también en los trofozoítos enquistantes de 24 horas (figura no mostrada) en los cuales estas proteínas disminuyen o no aparecen. Además, se observan, en las células enquistantes, nuevas proteínas muy intensas en un peso molecular de $\sim 60 \mathrm{kDa}$ con puntos isoeléctricos de 4,8 y 7,0 asignadas a las proteínas CWP1 y CWP2, respectivamente. Estas proteínas son carac-terísticas del quiste, las más prominentes de su pared; por tanto, una razón de mucho peso para su identificación.

Es evidente que el patrón de expresión de las proteínas en los dos estadios es diferente. Resulta notorio que para el quiste -que es la forma de vida latente del parásito- hay un silencio o disminución de la síntesis de proteínas. Este hecho se debe investigar con más profundidad.

\section{Discusión}

Una primera aproximación in vitro a la comprensión de la enquistación de Giardia es la simulación de aquellas condiciones a las que se ve sometido el parásito en el sistema digestivo del hospedero, que promoverían sucesos moleculares que lo llevarían a diferenciarse. Una de esas condiciones es la presencia de bilis. En nuestros experimentos, la adición de bilis bovina al medio TYI-S-33 indujo la enquistación en cultivos axénicos de Giardia. En este trabajo encontramos un rango amplio de concentración de bilis, de 5 a $7,5 \mathrm{mg} / \mathrm{ml}$, que indujo eficientemente ( $5-13 \%)$ la enquistación, datos que están de acuerdo con lo informado por Gillin et al. (14). En otros ensayos se pudo obtener alta enquistación con concentraciones tan bajas como 


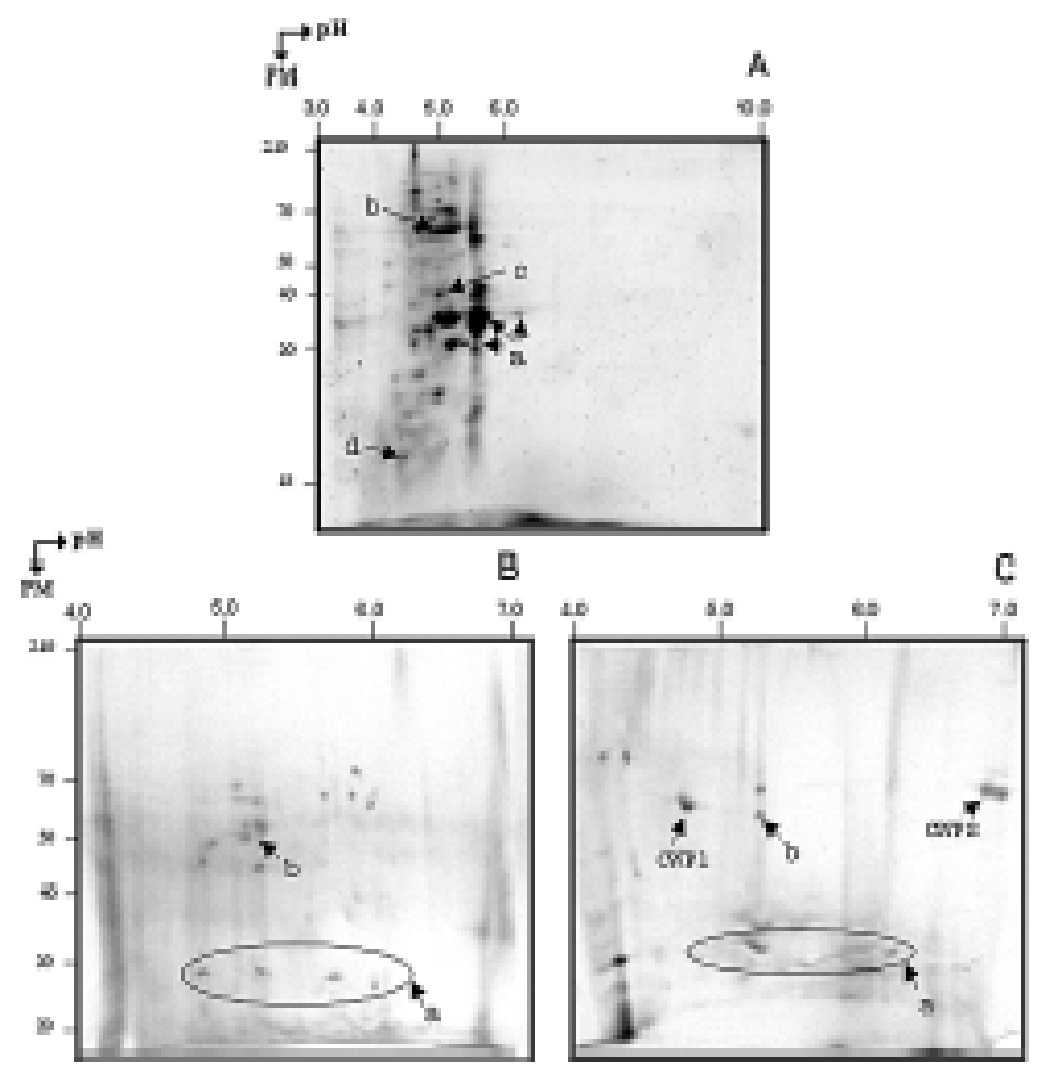

Figura 5. Separación bidimensional de proteínas de Giardia lamblia. A. Proteínas de trofozoíto en gel 15\% pH 3-10, teñido con Sypro ${ }^{\mathrm{TM}}$ Orange Stain. B. Proteínas de trofozoíto en gel 10\%, pH 4-7, teñido con plata. C. Células enquistantes con 48 horas de estímulo en gel 10\%, pH 4-7, teñido con plata. PM, peso molecular en kDa.

$1,5 \mathrm{mg} / \mathrm{ml}$. Se notó en nuestros experimentos que el número total de células (trofozoítos más quistes) decreció con concentraciones de bilis superiores a $2 \mathrm{mg} / \mathrm{ml}$ (datos no mostrados). Estos resultados parecerían indicar que es necesario que los parásitos estén en buenas condiciones fisiológicas y que se puedan dividir para enquistar, de tal forma que la eficiencia óptima de enquistación se logra en la concentración más alta de bilis que aún no disminuye el crecimiento del cultivo.

La duración del estímulo de la enquistación resultó ser un factor importante en el proceso. Con un método adaptado a partir del informado por el grupo de Kane et al. (15), se concluyó que una limitada exposición al medio de enquistación
(24 horas) seguida de un retorno al medio de crecimiento normal, que no es tóxico, puede ser suficiente para inducir la diferenciación al valor máximo sin afectar la viabilidad del parásito enquistado. Se observó, igualmente, que la enquistación in vitro se ve afectada por el tamaño del inóculo de trofozoítos de partida que van a ser sometidos a la diferenciación, como se muestra en las figuras $1 \mathrm{~A}$ y $1 \mathrm{~B}$, donde los inóculos muy grandes $\left(2 \times 10^{6}\right.$ trofozoítos $\left./ \mathrm{ml}\right)$ resultaron ineficientes, seguramente debido a que se encuentran cercanos a la densidad máxima del cultivo y no permiten una división de todos los trofozoítos durante el período de inducción. Los inóculos que oscilaron entre 1 y $1,2 \times 10^{6}$ trofozoítos $/ \mathrm{ml}$ resultaron ser los más 
convenientes para alcanzar niveles de enquistación aceptables.

La apariencia morfológica general de G. lamblia se observó por medio de microscopía de luz y electrónica de transmisión, antes, durante y después de la enquistación. Los trofozoítos tienen un tamaño de $8 \mu \mathrm{m}$ de ancho $\times 12 \mu \mathrm{m}$ de largo, aproximadamente, forma de pera y son distinguibles los dos núcleos característicos, los cuerpos medianos y los flagelos (figura 2). Las medidas y características de algunos organelos se corroboraron por medio de micrografías electrónicas de transmisión (figura 3), en donde se detallaron las estructuras componentes del disco ventral (conjunto de microcintas y microtúbulos) que es indispensable para la adhesión de Giardia a la mucosa intestinal y los axonemas flagelares, las vacuolas periféricas y los núcleos.

En los quistes de G. lamblia obtenidos in vitro se pueden observar dos morfologías claramente distinguibles de acuerdo con la apariencia de su citoplasma. Esto podría concordar con lo referido por Gillin et al. (14), quienes los discriminaron en los grupos I y II (viables y no viables, respectivamente). En el primer grupo clasificaron los quistes de apariencia lisa, forma oval y con un espacio peritrófico pequeño, como se observa en la figura 3B, mientras que a la segunda categoría pertenecen los quistes con citoplasma recogido, un amplio espacio peritrófico a la pared, como el marcado con flecha en la figura citada.

Aunque la morfología ultraestructural de los quistes de Giardia sólo se pudo definir parcialmente, se encontraron elementos estructurales novedosos, distintos a los informados por otros grupos. Los quistes observados tenían pocos organelos distinguibles, los más claros son los núcleos y una larga hilera de estructuras aparentemente microtubulares que bordean internamente la membrana (figura 3, panel c). Esto puede ser interesante y es un problema en el cual el grupo de investigación continuará indagando.

El análisis electroforético de las proteínas de $G$. lamblia mostró aspectos interesantes en el patrón de expresión de los dos estadios de vida y corroboró algunos resultados ya disponibles en bases de datos proteómicas. En una apreciación general de las proteínas de Giardia, se encontró que la gran mayoría son de naturaleza ácida en un rango de puntos isoeléctricos entre 3 y 7 (figura $5 A$ ). Como el objetivo del presente trabajo era observar las diferencias en la expresión de proteínas en los dos estadios de vida, sólo se pudieron hacer aproximaciones a la identidad de algunas proteínas encontradas. Una caracterización más amplia requeriría métodos especiales como espectrometría de masas y secuenciación de proteínas, entre otros, que no hacen parte de los alcances de esta investigación.

Las giardinas están localizadas en las microcintas del disco ventral de Giardia; los estudios realizados por el grupo de Clark y Holberton (16) encontraron que estas proteínas estaban definidas en 5 bandas en electroforesis SDSPAGE unidimensional, como las que se muestran encerradas en la elipse de la figura 4 , con masas moleculares cercanas a $\sim 30 \mathrm{kDa}$. Durante la enquistación, el trofozoíto debe realizar importantes cambios, incluidos la división nuclear, el desmantelamiento y empaque de organelos, tales como el disco adhesivo, y la producción, procesamiento y transporte de los componentes de una pared protectora característica del estadio de quiste. Se observó un cambio en el patrón de expresión de las proteínas en puntos claves del proceso, como lo muestra la figura 5. Hay una disminución general de las proteínas encontradas en el rango de pl estudiado en las células enquistantes de 48 horas, en las que muy notoriamente sucede una síntesis de proteínas nuevas que se señalan en la figura con flechas marcadas y concuerdan con CWP1 y CWP2. Esta asignación se realizó porque éstas son proteínas exclusivas del quiste de Giardia. Son proteínas ricas en leucina, se dirigen a una vía secretoria por medio de un péptido señal amino-terminal y se ha postulado que la conformación de sus repetidos de leucina promueven las interacciones proteína-proteína (15). Los genes CWP1 y CWP2 predicen proteínas de naturaleza ácida con masas moleculares de 26 y 39 kDa, respectivamente; tienen una identidad en la secuencia de aminoácidos del $61 \%$ en el 
fragmento de $26 \mathrm{kDa}$ que tienen en común, pero la CWP2 tiene una extensión C-terminal de 121 residuos. Es rica en aminoácidos básicos, lo que hace que esta proteína tenga un pl calculado de 12 (4). Los resultados exhibidos en este estudio muestran que la CWP1 y la CWP2 tienen una masa aproximada de $\sim 60 \mathrm{kDa}$ con pl de $\sim 4,8$ y $>7,0$, respectiva-mente. Se ha encontrado que se pueden presentar entrecruzamientos intermoleculares y una alta glicosilación de estas proteínas (posiblemente por $\mathrm{N}$-acetilgalactosamina, el azúcar mayoritario de la pared, en los abundantes sitios potenciales de O- y Nglicosilación), lo que hace que se vean como una mancha intensa de alto peso molecular y movilidad relativa cercana a los $\sim 55 \mathrm{kDa}$ (4). Esta situación puede explicar el resultado obtenido que hace que las proteínas migren de una forma alterada en geles SDS-poliacrilamida.

\section{Agradecimientos}

Los autores agradecen a Sofía Duque y Adriana Arévalo del Laboratorio de Parasitología del Instituto Nacional de Salud por su invaluable ayuda en el manejo del cultivo de los parásitos y a Yolanda Porras por su asistencia técnica en microscopía. Este trabajo fue financiado por la Universidad Nacional de Colombia (DIB), por el Instituto Nacional de Salud y por el Instituto Colombiano para la Promoción de la Ciencia "Francisco José de Caldas" COLCIENCIAS, proyecto 1101-05-10060.

\section{Referencias}

1. Adam RD. The biology of Giardia spp. Microbiol Rev 1991;5:706-732.

2. Sogin ML. Early evolution and the origin of eukaryotes. Curr Opin Genet Dev 1991;1:457-63.

3. Gillin FD, Reiner DS, Gault MJ, Douglas H, Das S, Wunderlich A, et al. Encystation and expression of cyst antigens by Giardia lamblia in vitro. Science 1987; 235:1040-3.

4. Lujan HD, Mowatt M, Nash T, Conrad J, Bowers B. Identification of a novel Giardia lamblia cyst wall protein with leucine-rich repeats. J Biol Chem 1998;270: 29307-13.

5. Diamond LS, Harlo, DR, Cunnick CC. A new medium for the axenic cultivation of Entamoeba histolytica and other Entamoeba. Trans R Soc Trop Med Hyg 1978;72: 431-2.

6. Keister D. Axenic culture of Giardia lamblia in TYI-S-33 medium supplemented with bile. Trans R Soc Trop Med Hyg 1983;77:487-8.

7. Coligan JE, Dunn BM, Speicher DW, Wingfield D, editors. Current protocols in protein science. New York: John Wiley \& Sons; 1995.

8. Celis J, Ratz G, Basse B, Lauridsen J, Celis A. High resolution two-dimensional gel electrophoresis of proteins: isoelectric focusing (IEF) and non-equilibrium $\mathrm{pH}$ gradient electrophoresis (NEPHGE). Cell biology: a laboratory handbook. San Diego, CA: Academic Press; 1994.

9. Morrissey JH. Silver stain for proteins in poly-acrylamide gels. A modified procedure with enhanced uniform sensitivity. Ann Biochem 1981;117:307-10.

10. Bastidas A, Santamaría L. Caracterización bioquímica de las fases preliminares al proceso de enquistación de Giardia lamblia (tesis). Bogotá, D.C.: Universidad Nacional de Colombia; 2001.

11. Schupp D, Erlandsen S. A new method to determine Giardia cyst viability: correlation of fluorescein diacetate and propidium iodide staining with animal infectivity. Appl Environ Microbiol 1987;53:704-7.

12. Peattie D, Alonso R, Hein A, Caulfield J. Ultrastructural localization of giardins to the edges of disk microribbons of Giardia lamblia and the nucleotide and deduced protein sequence of alpha giardin. J Cell Biol 1989;109:2323-35.

13. Heyworth M, Foell J, Sell T. Giardia muris: evidence for a b-Giardin homologue. Exp Parasitol 1989;91:284-7.

14. Gillin F, Boucher S, Rossi S, Reiner D. Giardia lamblia: the roles of bile, lactic acid, and $\mathrm{pH}$ in the completion of the life cycle in vitro. Exp Parasitol 1989; 69:164-74.

15. Kane A, Ward H, Keush G, Pereira M. In vitro encystation of Giardia lamblia: large-scale production of in vitro cysts and strain and clone differences in encystation efficiency. J Parasitol 1991;77:974-81.

16. Clark J, Holberton D. Triton-labile antigens in flagella isolated from Giardia lamblia. Parasitol Res 1988;74: 415-23. 